\title{
Citologia do derrame papilar
}

\author{
Cytology of nipple discharge
}

Carlos Eduardo de Andrea'; Ana Cristina Lira Sobral'; Élide Sbardellotto Mariano da Costa2; Joel T. Totsuguiं3; Samuel Regis de Araújo ${ }^{4}$; Luiz Martins Collaço ${ }^{5}$

\begin{abstract}
unitermos
Derrame papilar

Citologia da descarga papilar

Câncer mamário

resumo

Introdução: A avaliação citológica do derrame papilar é um método bem estabelecido para o diagnóstico rápido de carcinoma mamário em mulheres. Objetivos: Estabelecer a freqüência das diferentes categorias diagnósticas, as características citomorfológicas das descargas papilares e, ainda, a relação entre o aspecto macroscópico dessas secreções e o citodiagnóstico. Material e método: O presente estudo analisou o resultado obtido do derrame papilar de 423 pacientes no período de janeiro de 1997 a abril de 2002. Os derrames foram classificados em positivo, negativo ou suspeito para células neoplásicas. Resultados: Dos 423 casos analisados, os derrames papilares foram positivos em quatro casos, suspeitos em 11 e negativos em 408. O aspecto macroscópico hemorrágico esteve presente em dois casos positivos, sete suspeitos e 62 negativos. Os achados citológicos mais freqüentes, nos casos positivos ou suspeitos, foram de grupamentos papilares de células epiteliais com hemácias ou células ductais com atipias. Discussão e conclusões: Com base nessa experiência, conclui-se que os esfregaços catalogados como hemorrágicos, macroscópica ou microscopicamente, devem ser cuidadosa e sistematicamente analisados, pois neles há uma maior possibilidade de serem detectadas lesões significativas.
\end{abstract}

abstract

Background: The cytological evaluation of nipple discharge is a well-known method for the fast diagnosis of breast carcinoma in females. Objectives: To establish the frequency of different diagnosis categories, the cytomorphologic features of nipple discharge and, in addition, the relationship between the macroscopic aspect of those secretions and cytodiagnosis. Material and method: This study examined the results obtained from 423 patients with nipple discharge during the period from January 1997 to April 2002. The discharges were classified in positive, negative or suspicious for neoplastic cells. Results: Of the 423 examined cases, nipple discharges were positive in four cases, suspicious in 11 and negative in 408. The bloody macroscopic appearance was present in two positive cases, suspicious in seven and negative in 62. The most frequent cytological features, in the positive or suspicious cases, were papillary clusters of epithelial cells with erythrocytes or ductal cells with atypical findings. Discussion and conclusions: Based on this experience, we concluded that the smears classified as bloody, macroscopic or microscopically, should be careful and systematically analyzed because there is a larger possibility of detecting significant lesions in them. key words

Nipple discharge

Nipple discharge cytology

Breast neoplasm

\footnotetext{
1. Médicos residentes em Anatomia Patológica do Hospital de Clínicas da Universidade Federal do Paraná (HC/UFPR).

2. Acadêmica de Medicina da UFPR.

3. Professor-assistente da disciplina de Anatomia Patológica da UFPR.

4. Médico patologista da Associação Paranaense de Patologia (APP).

5. Professor-adjunto da disciplina de Anatomia Patológica da UFPR.
} 


\section{Introdução}

Descarga ou derrame papilar é a saída de secreção através da papila mamária, quando não associada à gravidez e à lactação (descarga papilar fisiológica). É o sintoma mais freqüente, depois do nódulo e da dor mamária, constituindo cerca de $7 \%$ das queixas das pacientes. É um sinal inespecífico, decorrente de causa mamária ou extramamária e, neste caso, pode ser encontrado em diversas situações, tanto no homem quanto na mulher, devido à estimulação do epitélio mamário por mecanismos neuroendócrinos, caracterizando assim a galactorréia ${ }^{(3)}$. O derrame do mamilo tem sido descrito em $10 \%$ a $15 \%$ das mulheres com doença benigna da mama e em $2,5 \%$ a $3 \%$ está relacionado com carcinoma $^{(8,10,14)}$.

A secreção é classificada, segundo seu aspecto macroscópico, em leitosa, verde, castanha, sangüínea, serosa, turva ou purulenta ${ }^{(1)}$. $O$ termo descarga papilar sangüínea ou hemorrágica só pode ser aplicado nos casos em que a secreção, à microscopia, revelar elementos hemáticos( ${ }^{(3)}$.

A importância do estudo dos derrames sangüíneos se deve à sua associação com papiloma intracanalicular, carcinoma papilífero e outras lesões ${ }^{(1)}$. Em homens, a relação do derrame papilar com o câncer de mama é maior do que em mulheres, estando presente em cerca de $20 \%$ dos homens com câncer de mama e sendo geralmente hemorrágico ${ }^{(3,9)}$.

O significado clínico do derrame papilar torna-se extremamente importante quando não existe nenhuma massa palpável na mama ${ }^{(4,6)}$.

O presente trabalho tem como finalidade avaliar a freqüência das diferentes categorias diagnósticas e o aspecto citomorfológico concomitante nas descargas papilares. O estudo tem ainda como objetivo estabelecer a relação entre o aspecto macroscópico dessas secreções e o citodiagnóstico.

\section{Material e método}

A casuística do presente estudo corresponde à análise de 423 amostras citológicas de descargas papilares provenientes de 423 pacientes do sexo feminino, no período de janeiro de 1997 a abril de 2002, atendidas pelo serviço de Anatomia Patológica do Hospital Nossa Senhora das Graças, Curitiba (PR), e através do Programa de Prevenção do Câncer Ginecológico do Estado do Paraná. As pacientes foram examinadas clinicamente e, a seguir, foi realizada a coleta do derrame papilar, sendo confeccionados de um a seis esfregaços citológicos de cada paciente. Dados clínicos relevantes, como informações quanto à lateralidade e características do derrame papilar, foram registrados.

Do ponto de vista macroscópico, os derrames papilares foram classificados em hemorrágico, seroso, leitoso (galactorréico) e não-especificado.

As preparações secas ao ar ou fixadas com álcool foram coradas pelos métodos de Giemsa (57 lâminas) ou Papanicolaou (366 lâminas). Elas foram classificadas, para fins diagnósticos, como positivas, negativas ou suspeitas para células neoplásicas, com laudo complementar descritivo dos elementos celulares presentes.

\section{Resultados}

Dos 423 casos analisados, a idade variou entre $14 \mathrm{e}$ 82 anos, sendo que em 34 pacientes (8\%) a idade não foi mencionada. A faixa etária que apresentou maior número de casos (159) foi a compreendida entre 30 e 39 anos (37,6\%), seguida pelas faixas de 40 a 49 anos, com 97 casos (22,9\%); 20 a 29 anos, com 65 casos (15,4\%); 50 a 59 anos, com 38 casos (9\%); 60 a 69 anos, com 17 casos (4\%); dez casos entre 14 e 20 anos $(2,4 \%)$ e três casos entre 70 e 89 anos $(0,7 \%)$.

Em relação à lateralidade, $24,6 \%$ dos casos analisados representavam derrame papilar em mama esquerda (104 casos); 30,7\% em mama direita (130 casos) e $25,3 \%$ em ambas as mamas (107 casos). Em 19,4\% dos casos constava como ignorado se a coleta do material fora uni ou bilateral (82 casos).

Quanto ao aspecto macroscópico do derrame papilar, 71 casos $(16,8 \%)$ foram hemorrágicos, 49 (11,6\%) sero-

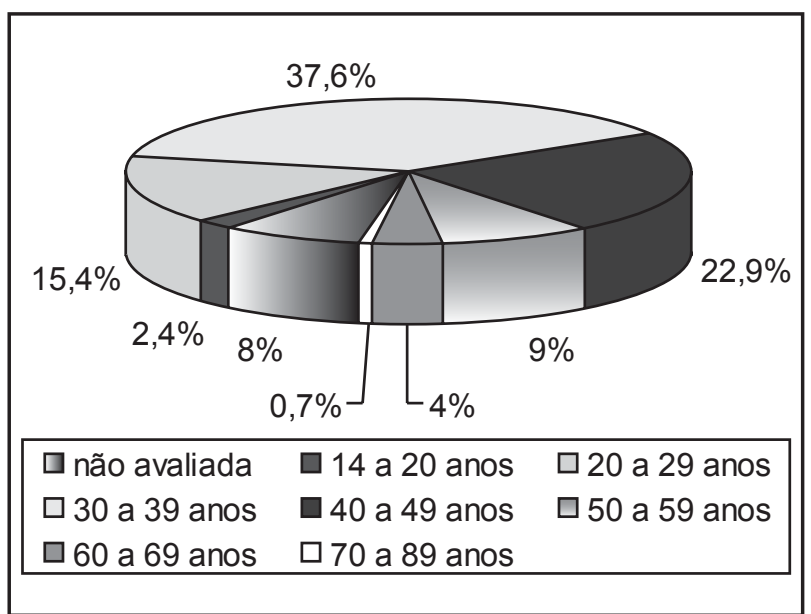

Figura 1 - Distribuição por faixa etária das pacientes do sexo feminino que apresentaram descarga papilar 
sos, nove $(2,1 \%)$ foram catalogados como galactorréicos e em 294 casos $(69,5 \%)$ o derrame foi classificado como não-especificado.

Correlacionando as características celulares que predominaram na microscopia com o aspecto macroscópico da descarga, 40 amostras apresentaram hemácias, sendo que desses casos 35\% foram classificados como derrames não-especificados ( 14 casos) e $65 \%$ como hemorrágicos (26 casos). Em 26 amostras identificaram-se células epiteliais, sendo que $61,54 \%$ foram classificados como derrames não-especificados (16 casos) e 38,46\% como hemorrágicos (dez casos).

Em 249 amostras encontraram-se células espumosas, sendo que $76,71 \%$ foram classificados como derrames não-especificados (191 casos), 9,64\% como hemorrágicos ( 24 casos), 11,24\% como serosos ( 28 casos) e 2,41\% como galactorréicos (seis casos). Em 93 amostras apareceram leucócitos, predominantemente neutrófilos, sendo que $72,04 \%$ foram classificados como derrames não-especificados (67 casos), 11,83\% como hemorrágicos (11 casos), $12,9 \%$ como serosos (12 casos) e 3,23\% como galactorréicos (três casos). Ainda 15 amostras foram classificadas como acelulares por apresentarem apenas material amorfo de fundo e negativas para malignidade. Dessas amostras, $40 \%$ foram classificadas como derrames não-especificados (seis casos) e $60 \%$ como serosos (nove casos).

Quanto ao diagnóstico citológico final, 408 casos $(96,4 \%)$ foram considerados negativos para malignidade, e destes, 288 amostras (70,59\%) haviam sido classificadas como derrames não-especificados, 62 (15,2\%) como hemorrágicos, 49 $(12,01 \%)$ como serosos e nove $(2,2 \%)$ como galactorréicos. Onze casos $(2,60 \%)$ foram considerados suspeitos para malignidade, e destes, quatro amostras (36,36\%) haviam sido classificadas como derrames não-especificados e sete $(63,64 \%)$ como hemorrágicos. Quatro casos $(0,9 \%)$ foram considerados positivos para malignidade, e destes, duas amostras (50\%) haviam sido classificadas como derrames não-especificados e duas (50\%) como hemorrágicos.

Em todos os casos suspeitos prevaleceram os esfregaços hemorrágicos com macrófagos e grupos papiliformes tridimensionais de células ductais com núcleos ovóides de cromatina homogênea. Já nos casos positivos para malignidade, os esfregaços continham células cuboidais atípicas, isoladas ou em pequenos blocos, com núcleos pleomorfos, hipercromáticos e de cromatina grosseira.

\section{Tabela 1 categoria diagnóstica e a quantidade de casos em que foram observadas}

\begin{tabular}{lc}
\hline Categoria diagnóstica & Número de casos (\%) \\
Negativo (408) & $249(61,03)$ \\
Células espumosas & $93(22,79)$ \\
Leucócitos, predominantemente neutrófilos & $40(9,8)$ \\
Hemácias & $11(2,7)$ \\
Células epiteliais sem atipias & $15(3,68)$ \\
Ausência de células, somente material amorfo de fundo & \\
Suspeito (11) & $11(100)$ \\
Células epiteliais com discretas atipias & $11(100)$ \\
Núcleos ovóides & $11(100)$ \\
Cromatina homogênea & \\
Outros elementos observados: freqüentes células espumosas, esparsos linfócitos e hemácias & \\
Positivo (4) & $4(100)$ \\
Células epiteliais com atipias & $4(100)$ \\
Núcleos pleomorfos & $4(100)$ \\
Nucléolo evidente & $4(100)$ \\
Cromatina grosseira & $4(100)$ \\
Células epiteliais isoladas & \\
Outros elementos observados: fundo hemático, raros linfócitos e neutrófilos
\end{tabular}




\section{Tabela 2 Descarga papilar: correlação entre 0 aspecto macroscópico das secreçōes e o citodiagnóstico}

\begin{tabular}{lcccc}
\hline \multirow{2}{*}{ Aspecto macroscópico } & \multicolumn{4}{c}{ Diagnóstico citológico } \\
\cline { 2 - 5 } & Negativo & Suspeito & Positivo & Total \\
Não-especificado & $288(70,59 \%)$ & $4(36,36 \%)$ & $2(50 \%)$ & 294 \\
Hemorrágico & $62(15,2 \%)$ & $7(63,64 \%)$ & $2(50 \%)$ & 71 \\
Seroso & $49(12,01 \%)$ & 0 & 0 & 49 \\
Galactorréia & $9(2,2 \%)$ & 0 & 0 & 9 \\
Total & 408 & 11 & 4 & 423 \\
\hline
\end{tabular}

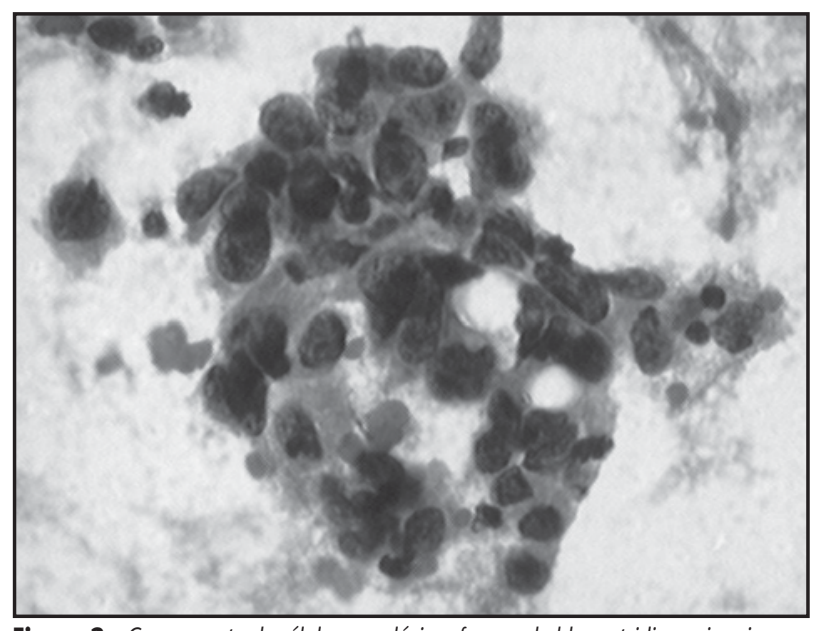

Figura 2 - Grupamento de células neoplásicas formando blocos tridimensionais, com arranjo glanduliforme e pleomorfos, hipercromáticos e de cromatina grosseira (coloração de Papanicolaou, 400x)

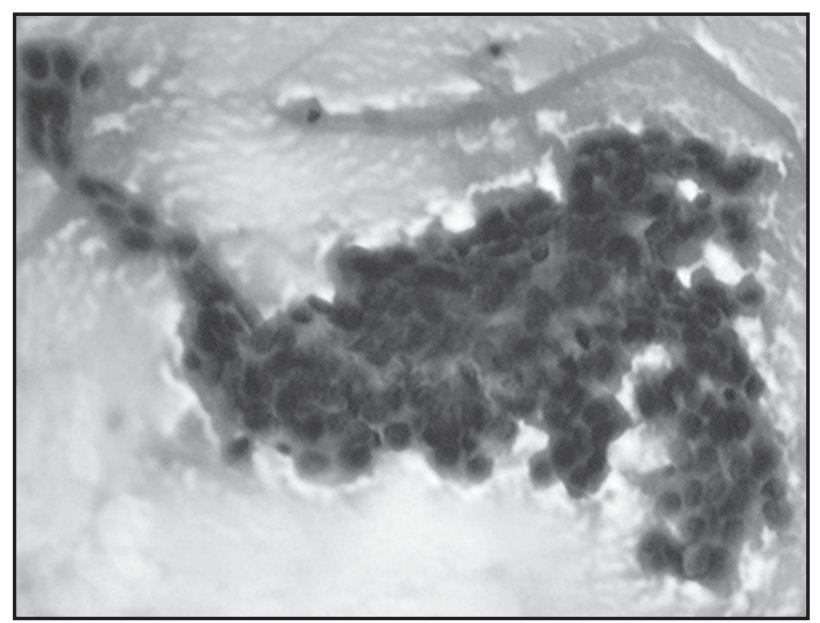

Figura 3 - Descarga papilar mostrando um grupamento papiliforme de células ductais benignas (coloração de Papanicolaou, 100x)

\section{Discussão e conclusões}

A citologia da descarga papilar é um exame inicial de rastreio e deve ser realizada nos casos de descarga papilar espontânea, preferencialmente na faixa etária de maior incidência de câncer de mama. Segundo Takeda et al., esse exame é passível de maior percentual de falso-negativos em relação aos resultados falso-positivos ${ }^{(13)}$. Como as células malignas não apresentam caráter citológico ou citoquímico particular, é necessária a análise de uma grande população celular para o diagnóstico correto ${ }^{(5)}$. Atribui-se a esse método menor sensibilidade em relação à punção aspirativa por agulha fina, uma vez que as células neoplásicas da mama tendem a diminuir e/ou desaparecer na descarga papilar, levando a uma baixa celularidade e tornando o diagnóstico mais difícil(3,5). Por outro lado, Lee destaca que não parece haver diferença significativa de especificidade entre a punção aspirativa por agulha fina e a citologia da descarga papilar ${ }^{(7)}$. O diagnóstico citológico das amostras de derrame do mamilo tem se mostrado extremamente bem-sucedido em associação a câncer central da região do mamilo e a papiloma ou doença papilar benigna ${ }^{(4,12)}$. Os derrames sangüíneos ou hemorrágicos sabidamente apresentam estreita relação com papilomas intracanaliculares, carcinomas papilíferos e outras lesões ${ }^{(1)}$. De acordo com Saphir(11), grupamentos de células epiteliais na citologia da secreção papilar são fortemente sugestivos de papiloma ou carcinoma. Para Donnelly ${ }^{(2)}$, 53\% de 115 pacientes com derrame papilar hemorrágico apresentavam um esfregaço citológico sugestivo de lesão maligna. Takeda ${ }^{(13)}$ conclui que grupamentos papilares compostos por mais de 30 células ductais são encontrados somente em casos de carcinoma ou papiloma, e que células ductais com atipias ou células ductais em grupamentos papilares com hemácias podem ser indicadores de carcinoma ou papiloma.

No total dos casos analisados no presente estudo, 15 mostraram-se suspeitos para malignidade ou malignos $(3,5 \%)$, sendo que na maioria deles (60\%) predominaram os esfregaços de aspecto hemorrágico. Com base nessa experiência, conclui-se que os esfregaços catalogados como hemorrágicos, macroscópica ou microscopicamente, devem ser cuidadosa e sistematicamente analisados, pois neles há maior possibilidade de serem detectadas lesões significativas. 


\section{Referências}

I. BLAND, K. I.; COPELAND III, E. M. A mama: tratamento compreensivo das doenças benignas e malignas. São Paulo, S.P.: Editora Manole, 1994.

2. DONNELLY, B. A. Nipple discharge: its clinical and pathologic significance. Ann Surg, v. I 31, n. 3, p. 342-55, 1950.

3. FRANCO, J. M. Mastologia - formação do especialista. São Paulo, S.P.: Editora Atheneu, 1997.

4. FUNDERBURK,W.W. et al. Evaluation of nipple discharge in benign and malignant diseases. Cancer, v. 24, n. 6, p. 1290-6, 1969.

5. HALBE, H. W. Tratado de Ginecologia. São Paulo, S.P.: Editora Roca, v. I, 1993.

6. KILGORE,A. R. et al.The incidence of cancer with nipple discharge and the risk of cancer in the presence of papillary disease of the breast. Surg Gynecol Obstet, v. 96, n. 6, p. 649-60, 1953.

7. LEE,W.Y. Cytology of abnormal nipple discharge: a cyto-histological correlation. Cytopathology, v. I4, n. I, p. 19-26, 2003.
8. LEIS, H. P. et al. Nipple discharge: significance and treatment. NY State J Med, v. 67, n. 23, p. 3105-10, 1967.

9. LÓPEZ-RÍOS, F. et al. Breast carcinoma in situ in a male. Report of a case diagnosed by nipple discharge cytology. Acta Cytol, v. 42, n. 3, p. 742-4, 1998

10. MURTA, E. F. C. et al. Descarga papilar.J Bras Ginecol, v. I04, n. I I/I2, p. 403-7, 1994.

I I.SAPHIR, O. Cytologic examination of breast secretion. Am J Clin Pathol, v. 20, n. II, p. I00 I- I0, 1950.

12. SHINZATO, J. Y. et al. Importância da descarga papilar na detecção precoce do câncer da mama.J Bras Ginecol, v. 104, n. 4, p. 8 I-5, 1994.

13.TAKEDA, T. et al. Nipple discharge cytology in mass screening for breast cancer. Acta Cytol, v. 34, n. 2, p. 161-4, 1990.

14. URBAN, J. et al. Non-lactational nipple discharge. CA Cancer J Clin, v. 28, n.3, p. I30-40, 1978 